\title{
IDENTIFYING THE ROLE OF NATIONAL DIGITAL CADASTRAL DATABASE (NDCDB) IN MALAYSIA AND FOR LAND-BASED ANALYSIS
}

\author{
N.Z.A. Halim ${ }^{\text {a }}$, S.A. Sulaiman ${ }^{\text {a }}$, K. Talib ${ }^{\text {a }}$, O.M. Yusof ${ }^{\text {a }}$, M.A.M. Wazir ${ }^{\text {a }}$, M.K. Adimin $^{\text {b }}$ \\ ${ }^{a}$ Center of Studies for Surveying Science and Geomatics, Faculty of Architecture, Planning and Survey, University \\ Technology Mara, Shah Alam, Malaysia - nurzurairah@gmail.com \\ ${ }^{\mathrm{b}}$ Cadastral Division, Department of Survey and Mapping Malaysia, Kuala Lumpur, Malaysia - kamali@jupem.gov.my
}

KEY WORDS: National Digital Cadastral Database, Delphi technique, disaster management

\begin{abstract}
:
This paper explains the process carried out in identifying the significant role of NDCDB in Malaysia specifically in the land-based analysis. The research was initially a part of a larger research exercise to identify the significance of NDCDB from the legal, technical, role and land-based analysis perspectives. The research methodology of applying the Delphi technique is substantially discussed in this paper. A heterogeneous panel of 14 experts was created to determine the importance of NDCDB from the role standpoint. Seven statements pertaining the significant role of NDCDB in Malaysia and land-based analysis were established after three rounds of consensus building. The agreed statements provided a clear definition to describe the important role of NDCDB in Malaysia and for land-based analysis, which was limitedly studied that lead to unclear perception to the general public and even the geospatial community. The connection of the statements with disaster management is discussed concisely at the end of the research.
\end{abstract}

\section{BACKGROUND}

\subsection{Role of land information for disaster management}

Land registers and cadastre have the role to play in supporting governments and citizens in their efforts at mitigating climate change and trying to adapt to its impact (Van der Molen, 2009a). For example, a land acquisition process of land or property that are exposed to disaster risk can be done to reduce the effect of such unwanted catastrophe as the decision can be made priorly from a land-based analysis, from the long-term perspective and sustainable measure (Banba, 2017). Mitchell, Enemark, and van der Molen (2015) have argued that effective land administration and management be a necessary prerequisite for improving adaptive capacity and for climate resilient urban development. They have drawn on literature that articulates how improved tenure security reduces vulnerability to natural disasters and the importance of addressing land issues in risk reduction. They have also outlined the benefits of improved land-use planning to climate risk factors and vulnerability, and concluded the information on the people to the land relationship is crucial for post-disaster management to enable spatially accurate land planning and redevelopment.

The cadastre is the engine of land administration systems which is responsible for registering the land parcel's rights, restrictions and responsibilities (Bennett, Wallace, \& Williamson, 2008). The combination of disaster risk information and cadastre information on land tenure, land value, and land use enables the required risk inhibition and mitigation measures to be identified and assessed in line with legal, economic, physical, and social consequences (Williamson, Enemark, Wallace, \& Rajabifard, 2010).

\subsection{Land Information System in Malaysia}

The cadastral system in Peninsular Malaysia and Federal Territory of Labuan consists two main components which are the land registry and the cadastral survey. Except for Sabah and Sarawak, the rest of the states in Malaysia adopts the Torrens System and strictly ties to the National Land Code, 1965 or NLC, 1965 and the respective state's land law and legislation. The land parcel's information of states adopting the NLC,1965 can be retrieved from the Computerised Land Registration System (SPTB), at their respective state land offices (Ismail, 2011). The information provides textual attributes such as the land's ownership, rights, restrictions, and responsibilities. The land parcel's spatial information, on the other hand, is shown as cadastral maps (Certified Plan and Title Plan) can be retrieved either as a hardcopy or a digital map. Maps have long served as a fundamental purpose of understanding the geographical context of a disaster, and with the ability of GIS today, certain aspects of disaster situation can be represented (Tomaszewski, 2014) and spatially analysed. A Title Plan provides a 1:1 link relationship between land parcels and land registration. Alternatively, the spatial information of the cadastral maps can be obtained from the National Digital Cadastral Database or NDCDB.

\subsection{National Digital Cadastral Database (NDCDB)}

NDCDB was developed to replace the drawbacks of the former Digital Cadastral Database (PDUK) that was predominantly GIS technology unfriendly and not survey accurate (Kadir et al., 2003). It houses more than 7 million cadastral fabrics' in vector form, which is the spatial component of the cadastral system in Peninsular Malaysia and Federal Territory Labuan (to be mention as Malaysia in this paper from this point onwards). 
The development of NDCDB included the 1st class and 2nd class survey information that was previously stored in PDUK, as well as the current 'free class' ones under the new eKadaster system (Yusoff \& Halim, 2012). The least square adjustment method was opted for network readjustment to meet the acceptable horizontal tolerances of $5 \mathrm{~cm}$ compared to the generic error method computed from loop closures of a closed traverse (JUPEM, 2012).

One of the main characteristics of NDCDB is the coordinate system adopts the Geocentric Cassini coordinate system and provides the positional spatial accuracy of $5 \mathrm{~cm}$ for urban areas and $10 \mathrm{~cm}$ for suburban areas. In other words, the spatial information is of survey accurate. Compared to PDUK, NDCDB was developed to be GIS friendly and available in either shapefiles or tab files. Each cadastral lots are also given a unique parcel identifier or UPI that responds as a foreign key for data relationship and attachments, thus enable data integration and data sharing. These characteristics permit NDCDB to be primarily used, but not exclusively, for spatial analysis. Even though the significance of the cadastral data has been discussed extensively internationally, the significant role of NDCDB in Malaysia specifically on land-based analysis is limitedly discussed. The situation has led to various perceptions and misinformation on NDCDB.

Generally, the societal impression of the cadastral data has been limitedly relevant to a single core statutory purpose of land registration that also included maintaining cadastral information consisting of rights, restrictions, and responsibilities (Van der Molen, 2009b). The same perception also applies in Malaysia where NDCDB is seen as a database that stores spatial information available in cadastral maps and nothing more. Nevertheless, a common stand was established among researchers (Mohamed, Chia, \& Chan, 1998; Nordin, 2001; Omar, Kadir, \& Sidek, 2006; Sim, 2012) that PDUK and now NDCDB, have impacted to the rise of GIS-based system development in Malaysia by multi-users.

\subsection{Methods for building decisions and form consensus}

In order to determine the significant role of NDCDB in Malaysia and evaluate its key themes, subjective insights and judgments on a collective basis from individuals with sundry expertise seemed appropriate. Among the best-known methodologies to achieve consensus are the Nominal Group Method and the Delphi technique (McMillan, King, \& Tully, 2016). The Nominal Group method gathers all participants at the same time and location commonly in a workshop, being a cost-effective and time-efficient method. The method, however, requires an accurate pre-planning from the moderator and participants, and availability of participants since they are assembled, face to face in a single session.

The Delphi technique, on the other hand, minimises the influence of individuals and maximises the reliability of results by providing anonymity to the participants. Their participants are typically experts with a specific criterion to the subject discussed. The Delphi technique has application whenever policies, plans, or ideas have to be based on informed judgment (Yousuf, 2007), and because of that, the Delphi technique was chosen in this study. Moreover, the technique provides a platform where consensus by subject matter experts can be achieved on a topic despite the limited evidence, lack of precise information and prior research (Avella, 2016; Yousuf, 2007).

Use of the web and conducting panel activities by e-mail is principally effective to meet the expert's busy timetable, logistics and provides Delphi participants with anonymity, privacy, and confidentiality. Equal status and equal opportunity to participate is permissible with anonymity. The disadvantages associated with face-to-face meetings such as personality influences or individual dominance can be avoided (Avella, 2016; McGeary, 2009) to elude influential result and inaccurate analysis.

\section{LITERATURE ON THE DELPHI TECHNIQUE}

\subsection{Overview of the Delphi Technique}

The Delphi technique is recognised as a consensus method, with the capability of providing insights for decision making (Förster \& von der Gracht, 2014) and enhance consensus building as well as consistency from a group of experts regarding a topic (McGeary, 2009; Tottossy, 2005). Yousuf (2007) highlighted the technique is suitable for gathering current and historical data that is vaguely known or unavailable, evaluating possible budget allocations, exploring urban and regional planning options, university campus and curriculum planning development, putting together an educational model, delineating the pros and cons associated with potential policy choices, distinguishing and clarifying real and perceived information and motivation, and exploring priorities of personal values, social goals, etc.

The Delphi technique, however, does not have a specific standard for adoption (Skulmoski, Hartman, \& Krahn, 2007). Instead, its method is flexible for modification to suit a research objective. Nevertheless, there are four distinct characteristics of the Delphi technique (Heiko, 2012; Rowe \& Wright, 1999), which are anonymity of participants, iteration process to determine the level of consensus, controlled feedback to ensure stability in responses and statistical "group response" to measure agreement and stability. A type of method that adheres to these characteristics is distinguished as the Classical Delphi technique, and most researchers (Avella, 2016; Förster \& von der Gracht, 2014; Kent \& Saffer, 2014; Markmann, Darkow, \& von der Gracht, 2013; McGeary, 2009; Skulmoski et al., 2007; Yang, 2003) agree that the method combines the qualitative and quantitative research design.

The steps commonly used in the Delphi technique from previous studies (Avella, 2016; Diamond et al., 2014; Holey, Feeley, Dixon, \& Whittaker, 2007; Kermanshachi, Dao, Shane, \& Anderson, 2016; McGeary, 2009; Ogbeifun, Agwa-Ejon, Mbohwa, \& Pretorius, 2016b; Skulmoski et al., 2007; Yang, 2003) can be summarised as follows: i) identifying and selecting the panel of experts; ii) getting consent and approval from the selected experts as the research participant and the Delphi panel member; iii) data collection from the panel where different types of either closed or open-ended questions can be used. Otherwise, the questions can be more structured to guide the Delphi participants towards the research objective; iv) qualitative, quantitative, or mix mode analysing data from the panel; v) collating information on a new questionnaire and send back to panel to evaluate; vi) compile every panel's evaluation 
and send back to each participant for comments and revision; vii) the panel of experts have the opportunity to provide brief written arguments to support their evaluations; viii) descriptive statistical analysis method on the compiled and revised panel evaluation; ix) the same panel of members are involved during each iterative process survey rounds, and $\mathrm{x}$ ) the survey round or iteration process is terminated the momment a full consensus or dissent are reached among panel experts.

The mode of interaction in the Delphi technique was initially paper and pen-based that consequently requires the panel to post relevant questionnaire or feedbacks either via snail mail or hand delivered. However, with the advent of ICT, panel activities and questionnaires can be communicated online and sent digitally to each participant through e-mail. Recent research was conducted to compare the result from both modes of interaction on the same issue, and the result indicates high similarity (Markmann et al., 2013; Ogbeifun, Agwa-Ejon, Mbohwa, \& Pretorius). Nonetheless, rapid turnarounds reduced operational cost and eliminating participant's mortality are among the advantages of optimising the later mode of interaction (Hanafin, 2004; McGeary, 2009).

\subsection{Participants}

Selecting experts to participate as a panel member is the utmost importance in the Delphi technique to ensure research reliability. Even so, there are no standards that stipulate the panel selection criteria. The selection of panel, however, is rigorous, should not be random, and must have an explicit criterion. Warth, Heiko, and Darkow (2013) highlighted four important criteria for selecting the experts in their study, which required experts to have: i) extensive knowledge and experience of the research topic; ii) willingness and commitment to participate; iii) sufficient time for panel activities; and iv) communication skills. To define a participant as an expert, some researchers added the panel selection criteria for the Delphi technique to meet the specific number of years the expert has experience and practicing in the specific study area (Kent \& Saffer, 2014; Ogbeifun et al., 2016a; Paul, 2014), while others impose professional body membership or certification, and senior designation or managerial levels in the specific study domain (Förster \& von der Gracht, 2014; Markmann et al., 2013).

The appropriate panel composition has never been established for this technique, but a heterogeneous panel of experts are preferred as indicated by previous research (Avella, 2016; Förster \& von der Gracht, 2014; Reefke \& Sundaram, 2017; Warth et al., 2013) to avoid invalid consensus among similarly thinking experts or bias in the result and non-representative domain experts. Nonetheless, covers the wider spectrum, the point of views and diverse perspectives. Heterogeneity includes aspects related to the panel's professional experience and knowledge. There is also no specific number of groups to establish a heterogeneous panel of experts. However, the literature shows two or three groups are common, and participation should be based on those groups most directly affected by the topic of the study (Avella, 2016). The probability of participants to have similar opinions may create a biased result (Förster \& von der Gracht, 2014) in a homogeneous panel since the panels have similar information base and desirability.
The standard size of the overall panel has also never been established. However, typical panels seem to fall in the 3 to more than 100-member range and consist of either two or three expert groups (Avella, 2016; Paul, 2014; Skulmoski et al., 2007) that should be balanced to eliminate group domination. Nevertheless the greater the heterogeneity of the group, the fewer number of experts are recommended where 5 to 10 members are considered ideal (Bueno \& Salmeron, 2008).

\subsection{Level of consensus}

Delphi studies have used subjective analysis, descriptive statistics, and inferential statistics for the definition of a stopping criterion in each iteration process. Apart from consensus measurement, researchers (Diamond et al., 2014; Förster \& von der Gracht, 2014; Heiko, 2012) recommended the stability or consistency be measured as well between panel responses in each iteration processes or rounds, to ensure accurate Delphi analysis and data interpretation. Reference (Heiko, 2012) and (Holey et al., 2007) added the elements of a reduced number of comments and evolution of statements to be a part of the stopping criterion as the indicators that consensus and stability have been reached in the Delphi study. The minimum round for consensus can be two but, three rounds are common in most studies (Holey et al., 2007). If group consensus is desirable and the sample is heterogeneous, then three or more rounds may be required (Skulmoski et al., 2007). Round one is generally the foundation for identifying issues of the research area, while the following rounds two and three are consensus building rounds (Reefke \& Sundaram, 2017).

\section{RESEARCH METHODOLOGY \& RESULT}

Considering all the inputs from the literature, the research methodology for this study has adopted the common steps of a Classical Delphi technique, recommendations from previous research and modification to suit the research questions. The following are the methodology carried out in identifying the significant role of NDCDB in Malaysia and for land-based analysis:

\subsection{Questionnaire design, validity, and reliability}

Questionnaires are the research instrument to collect data in this study. In designing the questionnaires for Round 1, open-ended close structured questions were formed based on the overall research framework. The Round 2 questionnaire was the result of the Round 1 qualitative analysis result. Given the importance of this study on policies revolving the usage of NDCDB specifically for land-based analysis, the research instruments which are the questionnaires were assessed for validity and pretested for reliability.

The open-ended close structured and close-ended close structured Questionnaire's content for Round 1, and Round 2 used in this study were validated by four experts who are either practitioners or academia. Content validity index (I-CVI) for individual questions were used where the experts were asked to review the relevance of each question on a 4-point Likert scale of 1-Extremely irrelevant, 2-not relevant, 3-relevant and 4-very relevant. Polit and Beck (2006) highlighted all experts must agree on the content validity of an item (I-CVI of 1.00) when the panel consists of five or fewer experts. All experts in this study were in agreement that all of the twelve questions related 
to the significant role of NDCDB in Malaysia and land-based analysis be very relevant, which resulted in the calculated I-CVI value as 1.00. Experts were also instructed to give comments on the questionnaire's readability, feasibility, layout and style, and clarity of wording, if relevant.

Pretesting is not common in the Delphi technique (Avella, 2016; Hanafin, 2004), but if conducted the recommended minimum participants are $10 \%$ of the actual panel size (Waweru \& Omwenga, 2015). Pretesting was performed of the Round 1 open-ended close structured questionnaire followed with the close-ended close structured questionnaire in Round 2 before the actual respective Delphi rounds. The pretesting was deemed necessary in this study to determine the reliability of the questionnaire in establishing whether the response to each question can be adequately interpreted in relation to the information required. Two rounds of test-retest pilot studies were carried out respectively for Round 1 and Round 2 questionnaires with three participants, which was more than the $10 \%$ numbers of participants recommended for pretesting. These participants provided comments and feedbacks, but their responses were not involved in the actual study. Participants in the pilot study have provided valuable feedback that contributed to the overall refinement of the study such as rephrasing questions, refine instructions and helps to identify unclear or ambiguous statements in the research protocol besides providing credibility to the entire research project.

\subsection{Composition and panel size}

Considering NDCDB has a direct association with the land, cadastre and GIS domain, a heterogeneous group of a panel of experts was set up in this study to diversify member's background and reduce bias result. The panel consists of experts involved directly in the decision-making process of their respective organisations. Initially, 18 potential members were carefully selected based on the 4 criterion used by previous Delphi researchers (Markmann et al., 2013; Warth et al., 2013), such as; i) number of years of job-relevant experience in their domain with 20 years as the threshold; ii) the expert's certification and accreditation to reflect their skills and knowledge; iii) current management level; and iv) labelled experts by social acclamation approach. Finally, the expert's responsibilities inside and outside of the organisation were also taken into consideration for panel selection (Avella, 2016; Markmann et al., 2013) in this study. The final totaled panel size throughout the Delphi process was 14 which can be summarized in three major groups: policy makers, interest group and stakeholders who are distinguished by individuals' professional experience as a specialist in Malaysia of either in the land, cadastre or GIS domain.

\subsection{Round 1}

After piloting, an email inviting participation, explaining the study, outlining the Delphi process and requesting responses to the question was sent to the potential participants. Simultaneously, participants were provided with an open-ended semi-structured questionnaire that has been pretested, to be completed by them. The questions were generally focused on the participants' expertise views based on themes of legal significance, technical significance, role significance and landbased analysis significance. However, the significance of the
NDCDB's role and land-based analysis theme are the focus of this paper.

Upon agreeing to participate the Delphi process, participants were initially given seven days to respond to the questionnaire questions, but some requested an extension of time due to the participant's busy schedule and commitments. A cut-off date was set to determine the timeline of Round 1. Out of 18 potential participants, 15 agreed to participate and returned the completed questionnaire through e-mail and hand-delivered, while 2 participants explained their busy schedule might hinder the study, and 1 participant did not return the questionnaire upon the cut-off date. Each response was of anonymity and was then compiled, collated and sent via e-mail to each participant, instead of a face-to-face group discussion. They were instructed to review the response from other anonymous respondents and were able to revise their responses within seven days. Only 2 participants had minor amendments by the cut-off date.

\subsection{Round 1 Result}

Responses from Round 1 were analysed by using the Thematic Analysis process. The qualitative data was firstly scrutinised, and emerging patterns or findings that were identified as nodes were processed using the Nvivo 11 Plus software. The nodes were listed under the Free Nodes theme. From the Free Nodes, a deductive approach was used to generate a Parent Node theme based on the research question and research objective, which focuses on the NDCDB's significant role in Malaysia and significant role for land-based analysis. Similar ideas related to the later theme were clustered together into emerging sub-themes. The emerging sub-themes were identified and named as shown in Table 1.

\begin{tabular}{|c|l|c|l|}
\hline No & $\begin{array}{l}\text { Emerging sub-themes } \\
\text { for NDCDB role in } \\
\text { Malaysia }\end{array}$ & No & $\begin{array}{l}\text { Emerging sub-themes for } \\
\text { NDCDB for land-based } \\
\text { analysis }\end{array}$ \\
\hline 1 & Reference datasets & 1 & $\begin{array}{l}\text { Sufficient knowledge on } \\
\text { NDCDB }\end{array}$ \\
\hline 2 & $\begin{array}{l}\text { Aid sustainable } \\
\text { development }\end{array}$ & 2 & $\begin{array}{l}\text { Means for correct adoption } \\
\text { of NDCDB }\end{array}$ \\
\hline 3 & $\begin{array}{l}\text { Support decision } \\
\text { making }\end{array}$ & 3 & $\begin{array}{l}\text { NDCDB as the } \\
\text { fundamental layer }\end{array}$ \\
\hline 4 & Planning activities & \multirow{2}{*}{4} & $\begin{array}{l}\text { Geocentric coordinated } \\
\text { system }\end{array}$ \\
\hline 5 & Spatial enabler & $\begin{array}{l}\text { Underpins national } \\
\text { development program }\end{array}$ & \\
\hline
\end{tabular}

Table 1: Emerging sub-themes for Parent Node Theme NDCDB Role and NDCDB for land-based analysis

Statements that best described the essence of the majority of opinions within each sub-theme in Table 1 were generated and presented in Table 2 and 3. These statements on the NDCDB's significant role in Malaysia and significant role for land-based analysis have provided the basis for Round 2.

\subsection{Round 2}

Participants were presented with an online questionnaire that includes both themed statements shown in Table 2 and 3. A five-point Likert scale was used to gather participant's opinion and perception on the statements and linguistic scales from 5 points as being "strongly agree", 4 points for "slightly agree", 3 


\begin{tabular}{|c|l|}
\hline No & \multicolumn{1}{|c|}{ Statements } \\
\hline 1 & $\begin{array}{l}\text { NDCDB is a spatial enabler that is also recognised as one of } \\
\text { the key geospatial reference frames in Malaysia which } \\
\text { facilitate the development of large-scale geospatial database } \\
\text { and large-scale Spatial Data Infrastructure that is essential } \\
\text { towards the conception of a spatially enabled platforms } \\
\text { nationwide. }\end{array}$ \\
\hline 2 & $\begin{array}{l}\text { NDCDB underpins the national land-based programs by } \\
\text { providing the homogeneity of a land parcel's legal status, its } \\
\text { geospatial information, and other relevant data so a cohesive } \\
\text { land-based spatial analysis can be performed, thus allowing } \\
\text { accurate decision-making specifically for sustainable land } \\
\text { governance. }\end{array}$ \\
\hline 3 & $\begin{array}{l}\text { NDCDB enables users to have cadastral fabrics that are a } \\
\text { reliable reference for land administrative purposes when the } \\
\text { land and people's relationship is the concern during } \\
\text { planning or development stages. }\end{array}$ \\
\hline
\end{tabular}

Table 2. Round 2 statements on NDCDB's significant role in Malaysia

\begin{tabular}{|c|l|}
\hline No & \multicolumn{1}{|c|}{ Statements } \\
\hline 1 & $\begin{array}{l}\text { NDCDB should be the fundamental dataset for any land- } \\
\text { based spatial analysis because it provides meaningful } \\
\text { insights on the land parcel's legal status and spatial } \\
\text { information relationship with other geospatial or non- } \\
\text { geospatial datasets. }\end{array}$ \\
\hline 2 & $\begin{array}{l}\text { NDCDB does improve the result of a land-based spatial } \\
\text { analysis once users have good comprehension on its } \\
\text { characteristics besides applying the correct adoption for } \\
\text { spatial analysis. }\end{array}$ \\
\hline 3 & $\begin{array}{l}\text { NDCDB is most suitable as base maps for planning } \\
\text { purposes specifically large-scale spatial analysis and long } \\
\text { distance network studies. }\end{array}$ \\
\hline 4 & $\begin{array}{l}\text { NDCDB enables other overlayed datasets and information } \\
\text { to be linked with Malaysia's geocentric datum and analyse } \\
\text { spatial data with survey accurate results. }\end{array}$ \\
\hline
\end{tabular}

Table 3. Round 2 statements on NDCDB's significant role in landbased analysis

\begin{tabular}{|c|c|c|c|c|c|c|c|c|c|c|c|}
\hline \multirow[b]{2}{*}{ Statement } & \multicolumn{5}{|c|}{ Round 2} & \multicolumn{5}{|c|}{ Round 3} & \multirow{2}{*}{$\begin{array}{c}\text { Mean } \\
\text { Percent } \\
\text { Change } \\
100 \% \\
\end{array}$} \\
\hline & $\mathbf{N}$ & IQR & Median & Mean & $\begin{array}{c}\text { Std. } \\
\text { Deviation }\end{array}$ & $\mathbf{N}$ & IQR & Median & Mean & $\begin{array}{c}\text { Std. } \\
\text { Deviation }\end{array}$ & \\
\hline Statement 1 & 14 & 1.00 & 5.00 & 4.64 & 0.497 & 14 & 1.00 & 5.00 & 4.71 & 0.469 & $1.40 \%$ \\
\hline Statement 2 & 14 & 1.00 & 5.00 & 4.64 & 0.497 & 14 & 0.00 & 5.00 & 4.79 & 0.426 & $3.00 \%$ \\
\hline Statement 3 & 14 & 1.00 & 5.00 & 4.57 & 0.514 & 14 & 1.00 & 5.00 & 4.86 & 0.363 & $5.80 \%$ \\
\hline
\end{tabular}

Table 4: Statistical analysis of Round 2 and 3 - NDCDB's role in Malaysia

\begin{tabular}{|c|c|c|c|c|c|c|c|c|c|c|c|}
\hline \multirow[b]{2}{*}{ Statement } & \multicolumn{5}{|c|}{ Round 2} & \multicolumn{5}{|c|}{ Round 3} & \multirow{2}{*}{$\begin{array}{c}\text { Mean } \\
\text { Percent } \\
\text { Change } \\
100 \% \\
\end{array}$} \\
\hline & $\mathbf{N}$ & IQR & Median & Mean & $\begin{array}{c}\text { Std } \\
\text { Deviation }\end{array}$ & $\mathbf{N}$ & IQR & Median & Mean & $\begin{array}{c}\text { Std } \\
\text { Deviation }\end{array}$ & \\
\hline Statement 1 & 14 & 1.00 & 5.00 & 4.57 & 0.514 & 14 & 0.00 & 5.00 & 4.93 & 0.267 & $7.20 \%$ \\
\hline Statement 2 & 14 & 1.00 & 4.00 & 4.43 & 0.514 & 14 & 0.00 & 5.00 & 4.79 & 0.426 & $7.20 \%$ \\
\hline Statement 3 & 14 & 1.00 & 5.00 & 4.57 & 0.514 & 14 & 0.00 & 5.00 & 4.79 & 0.426 & $4.40 \%$ \\
\hline Statement 4 & 14 & 1.00 & 4.50 & 4.50 & 0.519 & 14 & 1.00 & 5.00 & 4.71 & 0.469 & $4.20 \%$ \\
\hline
\end{tabular}

Table 5: Statistical analysis of Round 2 and 3 - NDCDB's role in land-based analysis

points for "less agree", 2 points as "disagree" ad lastly 1 point as "strongly disagree". Neutral answer scale was not a choice because of it is equivalent to a no-judgement situation, whereas the Delphi technique should promote a discussion or otherwise to reduce bias result. Five-point or seven-point scales are generally preferred since smaller scales cannot transmit as much information and can stifle respondents whereas larger scales are less accurate (Reefke \& Sundaram, 2017). Space was provided for optional comments justifying their scale allocation decisions. All 15 original participants were offered via e-mail to participate in Round 2 and were requested to respond within seven days. Similar to Round 1, each response was of anonymity and were then compiled, collated and sent via e-mail to each participant who was then instructed to review the response from other anonymous respondents and was able to revise their responses within seven days. Only comments were added by the cut-off date.

\subsection{Round 2 Result}

The number of participants allocating points to each statement in Round 2 was totaled as 14.1 participant was transferred to a new agency and had to be withdrawn from the panel member. Likert scale points allocated were analysed with descriptive statistics using SPSS version 23 software, and statements with means lower than four are respectively removed. However, none were eliminated in this round as the means were higher than 4.00 as shown in Table 4 and 5. Additional comments received suggested minor amendments which required statements to be rephrased appropriately with the aim of moving towards group consensus and stability, as presented in Table 6 and 7.

\subsection{Round 3}

The Round 2 methodology was repeated, but with the original Statement 1 and rephrased Statement 2 and 3 for NDCDB's role in Malaysia while rephrased Statement 1 and 2, and original 
Statement 3 and 4 for NDCDB's role in the land-based analysis was the basis for Round 3 questionnaire. 14 participants were offered to participate in Round 3 and were requested to respond within three days.

\subsection{Round 3 Result}

The number of respondents received in Round 3 was totaled as 14 or $100 \%$ feedback. Similar to Round 2, the Likert scale point's responses were analysed with descriptive statistics. The increase in mean values was found in the rephrased statements as stated in Table 5 and 6 , with means value are more than 4.50 . The Median and Interquartile Range (IQR) are best statistical choices to measure central tendency and dispersion to calculate data scored on an ordinal scale in Delphi processes (Heiko, 2012). The median values in Round 3 were all 5.0 while the IQR values were within 0.00 to 1.00 , which is suitable as consensus indicator for 5-unit scales (Yang, 2003). The values showed consistency and high agreement, and therefore it was decided the Delphi process has come to a group consensus and stability which in result supports the decision that further Delphi rounds were unnecessary. Moreover, additional comments were not received in this round.

\section{ANALYSIS}

\subsection{Statistical result analysis}

Analysis of the Delphi technique results showed a change in participants' views towards consensus (agreement) and stability in Round 3. Therefore, the Delphi is concluded to have reach panel consensus and stability in Round 3 as indicated by a trend towards the following:

i. The median for the 5-Point Likert scale is the highest measure (5 - "strongly agree") to all statements;

ii. The IQR values are within 0.00 to 1.00 which indicate high agreement (Peck \& Devore, 2011);

iii. The increase of mean values in each round;

iv. Percent change between each statement from both rounds are less than $15 \%$ and is considered stable (Diamond et al., 2014; Heiko, 2012);

v. A decrease in comments in each round; and

vi. The evolution of statements towards consensus

\subsection{Agreed statements on the significant role of NDCDB in Malaysia}

The statements agreed by the members of Delphi panel describing the significant role of NDCDB in Malaysia are established as follows:

Statement 1: NDCDB is a spatial enabler that is also recognised as one of the key geospatial reference frames in Malaysia which facilitate the development of large-scale geospatial database and large-scale Spatial Data Infrastructure that is essential towards the conception of a spatially enabled platforms nationwide.

Statement 2: NDCDB underpins the national land-based programs by providing the homogeneity of a land parcel's legal status, its geospatial information, and other relevant data so a cohesive land-based spatial analysis can be performed to support sustainable land governance.
Statement 3: NDCDB provides reliable references of cadastral fabrics for land administrative purposes when the land and people's relationship becomes the concern for accurate decision making during planning or development stages.

\subsection{Agreed statement on the significant role of NDCDB for land-based analysis}

The statements agreed by the members of Delphi panel describing the significant role of NDCDB for land-based analysis are established as follows:

Statement 1: NDCDB should be recognised as the fundamental dataset for land-based spatial analysis because it provides meaningful insights on the land parcel's legal status and spatial information relationship with other geospatial or nongeospatial datasets.

Statement 2: $N D C D B$ can help provide the required result of a land-based spatial analysis when users understand its characteristics and know how to correctly adopt it for spatial analysis.

Statement 3: $N D C D B$ is most suitable as base maps for planning purposes specifically large-scale spatial analysis and long distance network studies.

Statement 4: NDCDB enables other overlayed datasets and information to be linked with Malaysia's geocentric datum and analyse spatial data with survey accurate results.

\section{DISCUSSION AND CONCLUSION}

The statements that best described the essence of the majority of opinions were critically analysed in Round 1 of this research. The majority of the Delphi panels highlighted that NDCDB would provide an impact in facilitating the concept of a spatially enabled society and government in Malaysia, and fundamental information for decision-makers when people and the land relationship is the concern in sustainable decisionmaking. The descriptions of the NDCDB's role in Malaysia and for land-based analysis were then transpired to the seven statements established in this research by using the Delphi technique. It can be concluded that NDCDB does have significant roles for land-based analysis, which is also essential for sustainable development in Malaysia.

Sustainable development has the direct linkage to disaster management (Ujang, 2017) and a spatially enabled society or government allows decision-making that can be associated with sustainability (Steudler, 2016). One can interpret and critically reflect on spatial information, interconnect with the assistance of maps and other spatial representations, and express location specific opinions using geoinformation and associated supports. NDCDB provides the spatial information and basic land information that is fundamental to spatial analysis. In other words, better judgement on land-based analysis which is crucial for disaster management is permissible by optimising NDCDB along with other related datasets. Accurate and timely information on land is the fundamental information to enable the concept (Bennett et al., 2008). 


\begin{tabular}{|c|l|l|}
\hline No & \multicolumn{1}{|c|}{ Statements } & \multicolumn{1}{|c|}{ Rephrased Statements } \\
\hline 1 & $\begin{array}{l}\text { NDCDB is a spatial enabler that is also recognised as one of the } \\
\text { key geospatial reference frames in Malaysia which facilitate the } \\
\text { development of large-scale geospatial database and large-scale } \\
\text { Spatial Data Infrastructure that is essential towards the } \\
\text { conception of a spatially enabled platforms nationwide. }\end{array}$ & No amendments. \\
\hline 2 & $\begin{array}{l}\text { NDCDB underpins the national land-based programs by } \\
\text { providing the homogeneity of a land parcel's legal status, its } \\
\text { geospatial information, and other relevant data so a cohesive } \\
\text { land-based spatial analysis can be performed, thus allowing } \\
\text { accurate decision-making specifically for sustainable land } \\
\text { governance. }\end{array}$ & $\begin{array}{l}\text { NDCDB underpins the national land-based programs by providing } \\
\text { the homogeneity of a land parcel's legal status, its geospatial } \\
\text { information, and other relevant data so a cohesive land-based spatial } \\
\text { analysis can be performed to support sustainable land governance. }\end{array}$ \\
\hline 3 & $\begin{array}{l}\text { NDCDB enables users to have cadastral fabrics that are a reliable } \\
\text { people's relationship is the concern during planning or } \\
\text { development stages. }\end{array}$ & $\begin{array}{l}\text { NDCDB provides reliable references of cadastral fabrics for land } \\
\text { administrative purposes when the land and people's relationship } \\
\text { becomes the concern for accurate decision making during planning } \\
\text { or development stages. }\end{array}$ \\
\hline
\end{tabular}

Table 6: Round 2 statements on NDCDB's significant role in Malaysia

\begin{tabular}{|c|l|l|}
\hline No & \multicolumn{1}{|c|}{ Statements } & \multicolumn{1}{c|}{ Rephrased Statements } \\
\hline 1 & $\begin{array}{l}\text { NDCDB should be the fundamental dataset for any land-based } \\
\text { spatial analysis because it provides meaningful insights on the } \\
\text { land parcel's legal status and spatial information relationship } \\
\text { with other geospatial or non-geospatial datasets. }\end{array}$ & $\begin{array}{l}\text { NDCDB should be recognised as the fundamental dataset for land- } \\
\text { based spatial analysis because it provides meaningful insights on the } \\
\text { land parcel's legal status and spatial information relationship with } \\
\text { other geospatial or non-geospatial datasets. }\end{array}$ \\
\hline 2 & $\begin{array}{l}\text { NDCDB does improve the result of a land-based spatial analysis } \\
\text { once users have good comprehension on its characteristics } \\
\text { besides applying the correct adoption for spatial analysis. }\end{array}$ & $\begin{array}{l}\text { NDCDB can help provide the required result of a land-based spatial } \\
\text { analysis when users understand its characteristics and know how to } \\
\text { correctly adopt it for spatial analysis. }\end{array}$ \\
\hline 3 & $\begin{array}{l}\text { NDCDB is most suitable as base maps for planning purposes } \\
\text { specifically large-scale spatial analysis and long distance network } \\
\text { studies. }\end{array}$ & No amendments. \\
\hline 4 & $\begin{array}{l}\text { NDCDB enables other overlayed datasets and information to be } \\
\text { linked with Malaysia's geocentric datum and analyse spatial data } \\
\text { with survey accurate results. }\end{array}$ & No amendments. \\
\hline
\end{tabular}

Table 7: Round 2 statements on NDCDB's significant role in land-based analysis

In fact, according to Steudler (2016) spatial is everywhere and our ability to leverage and harness the ubiquity of spatial information will correlate to benefits in terms of wealth creation, social stability and environmental management.

Both disaster management and sustainable development require sound land governance to reduce the impacts of climate change and post-disaster effects (Ujang, 2017). A sound land governance is where issues pertaining land are administered, and managed with emphasis given to the relations between people, policies and places in support of sustainability and the global agendas.

Among the many global agenda goals listed in Agenda 2030 mostly relates to the integral role of land, cadastre, and people in adapting to climate change, disaster recovery, environmental degradation and rapid urbanisation (UN, 2015). With these statements on NDCDB are in place, the clear description of NDCDB's role could encourage more research to be done, and NDCDB can be optimised by decision makers to aid land-based decision-making that also includes for disaster management and post-disaster effects analysis.

\section{CONTRIBUTION}

This study has contributed to the existing body of knowledge in understanding the NDCDB. Previously, there were limited empirical data available on unfolding the significance of NDCDB, specifically concerning its role in Malaysia and for land-based analysis. This research has helped to describe the importance of NDCB based on the consensus of experts related to land, cadaster and GIS domain by optimising the Delphi technique. The outcome of this research provides a new paradigm to the existing perception of the NDCDB and statements that aids land surveyors, land administrators, and GIS users, as well as the general public, to recognize its role in the nation and for land-based analysis. With the statements in place, it is hoped the usage of NDCDB for land-based analysis increases to encourage spatially accurate analysis result, including in the disaster management domain. 


\section{ACKNOWLEDGEMENTS}

The authors would like to Universiti Teknologi MARA, DSMM, and all related agencies for providing valuable information for this study. Thanks are also due to all my colleagues who assisted during this study data and last, but not least the unknown reviewers are gratefully acknowledged.

\section{REFERENCES}

Avella, J. R. (2016). Delphi Panels: Research Design, Procedures, Advantages, and Challenges. International Journal of Doctoral Studies, 11.

Banba, M. (2017). Land Use Management and Risk Communication. In M. Banba \& R. Shaw (Eds.), Land Use Management in Disaster Risk Reduction: Practice and Cases from a Global Perspective (pp. 13-17). Tokyo: Springer Japan.

Bennett, R., Wallace, J., \& Williamson, I. (2008). Organising land information for sustainable land administration. Land Use Policy, 25(1), 126-138. doi:http://dx.doi.org/10.1016/j.landusepol.2007.03.006

Bueno, S., \& Salmeron, J. L. (2008). Fuzzy modeling Enterprise Resource Planning tool selection. Computer $\begin{array}{llll}\text { Standards \& Interfaces, } & 30(3), \quad 137-147 .\end{array}$ doi:https://doi.org/10.1016/j.csi.2007.08.001

Diamond, I. R., Grant, R. C., Feldman, B. M., Pencharz, P. B., Ling, S. C., Moore, A. M., \& Wales, P. W. (2014). Defining consensus: a systematic review recommends methodologic criteria for reporting of Delphi studies. Journal of clinical epidemiology, 67(4), 401-409.

Förster, B., \& von der Gracht, H. (2014). Assessing Delphi panel composition for strategic foresight-A comparison of panels based on company-internal and external participants. Technological forecasting and social change, 84, 215-229.

Hanafin, S. (2004). Review of literature on the Delphi Technique. Dublin: National Children's Office.

Heiko, A. (2012). Consensus measurement in Delphi studies: review and implications for future quality assurance. Technological forecasting and social change, 79(8), 1525-1536.

Holey, E. A., Feeley, J. L., Dixon, J., \& Whittaker, V. J. (2007). An exploration of the use of simple statistics to measure consensus and stability in Delphi studies. BMC Medical Research Methodology, 7(1), 52.

Ismail, M. S. (2011). National Land Code 1965: Electronic Land Administration System In Land Registries. Jurnal Pentadbiran Tanah, Bil 1/2011, 20.

JUPEM. (2012). Final Report JUPEM T8/2011 Memperkasakan NDCDB. JUPEM: JUPEM.

Kadir, M., Ses, S., Omar, K., Desa, G., Omar, A. H., Taib, K., \& Nordin, S. (2003). Geocentric datum GDM2000 for Malaysia: Implementation and implications. Paper presented at the Seminar on GDM2000, Department of Survey and Mapping Malaysia, Kuala Lumpur, Malaysia.
Kent, M. L., \& Saffer, A. J. (2014). A Delphi study of the future of new technology research in public relations. Public Relations Review, 40(3), 568-576.

Kermanshachi, S., Dao, B., Shane, J., \& Anderson, S. (2016). Project Complexity Indicators and Management Strategies - A Delphi Study. Procedia Engineering, 145, 587-594. doi:http://dx.doi.org/10.1016/j.proeng.2016.04.048

Markmann, C., Darkow, I.-L., \& von der Gracht, H. (2013). A Delphi-based risk analysis-Identifying and assessing future challenges for supply chain security in a multi-stakeholder environment. Technological forecasting and social change, 80(9), 1815-1833.

McGeary, J. (2009). A critique of using the Delphi technique for assessing evaluation capability-building needs. Evaluation Journal of Australasia, 9(1), 31.

McMillan, S. S., King, M., \& Tully, M. P. (2016). How to use the nominal group and Delphi techniques. International Journal of Clinical Pharmacy, 38(3), 655-662. doi:10.1007/s11096-0160257-x

Mitchell, D., Enemark, S., \& van der Molen, P. (2015). Climate resilient urban development: Why responsible land governance is important. Land Use Policy, 48, 190-198. doi:http://dx.doi.org/10.1016/j.landusepol.2015.05.026

Mohamed, A. M., Chia, W. T., \& Chan, H. S. (1998). Cadastral Reforms in Malaysia. Paper presented at the XXI FIG Congrees, Brighton, United Kingdom.

Nordin, A. F. (2001). Institutional Issues in the Implementation of the Coordinated Cadastral System for Peninsular Malaysia: A Study on the Legal and Organizational Aspects. (Masters), Universiti Teknologi Malaysia.

Ogbeifun, E., Agwa-Ejon, J., Mbohwa, C., \& Pretorius, J. (2016a). The Delphi technique: A credible research methodology. Paper presented at the International Conference on Industrial Engineering and Operations Management, Kuala Lumpur.

Ogbeifun, E., Agwa-Ejon, J., Mbohwa, C., \& Pretorius, J. (2016b). The Delphi technique: A credible research methodology.

Omar, A. H., Kadir, A. M. A., \& Sidek, R. M. S. (2006). Development of Automated Cadastral Database Selection And Visualization System To Support The Realization of Modern Cadastre In Malaysia. Retrieved from

Paul, S. A. (2014). Assessment of critical thinking: A Delphi study. Nurse Education Today, 34(11), 1357-1360. doi:https://doi.org/10.1016/j.nedt.2014.03.008

Peck, R., \& Devore, J. L. (2011). Statistics: The exploration \& analysis of data: Cengage Learning.

Polit, D. F., \& Beck, C. T. (2006). The content validity index: are you sure you know what's being reported? Critique and recommendations. Research in nursing \& health, 29(5), 489497. 
Reefke, H., \& Sundaram, D. (2017). Key themes and research opportunities in sustainable supply chain management identification and evaluation. Omega, 66, Part B, 195-211. doi:https://doi.org/10.1016/j.omega.2016.02.003

Rowe, G., \& Wright, G. (1999). The Delphi technique as a forecasting tool: issues and analysis. International journal of forecasting, 15(4), 353-375.

Sim, C. Y. (2012). Investigation of data models and related requirements affecting the implementation of a multipurpose cadastre system in Malaysia. (Master Dissertation/Thesis), University of Glasgow.

Skulmoski, G. J., Hartman, F. T., \& Krahn, J. (2007). The Delphi method for graduate research. Journal of information technology education, 6,1 .

Steudler, D. (2016). The Six Fundamental Elements for Spatially Enabled Societies From a Fit-For-Purpose Perspective. Paper presented at the World Bank Conference on Land and Poverty, Washington DC.

Tomaszewski, B. (2014). Geographic Information Systems (GIS) for Disaster Management. Florida: CRC Press.

Tottossy, A. P. (2005). Teacher selection: A Delphi study. Virginia Polytechnic Institute and State University.

Ujang, Z. (2017). Contribution of research for Sustainable Social Development. Paper presented at the International Symposium on Disaster Risk Managemet 2017, Kuala Lumpur.

UN. (2015). Transforming Our World: The 2030 Agenda for Sustainable Development. Resolution adopted by the General Assembly on 25 September 2015. (A/RES/70/1). New York: United Nation Retrieved from http://www.un.org/ga/search/view_doc.asp?symbol=A/RES/70/ $1 \&$ Lang=E.

Van der Molen, P. (2009a). Cadastres and climate change. PositionIT, 19 - Jan/Feb 2010, 17-21.

Van der Molen, P. (2009b). The Evolving Function of Land Administration in Society. Paper presented at the 7th FIG Regional Conference, Hanoi, Vietnam.

Warth, J., Heiko, A., \& Darkow, I.-L. (2013). A dissent-based approach for multi-stakeholder scenario development-the future of electric drive vehicles. Technological forecasting and social change, 80(4), 566-583.

Waweru, P. K., \& Omwenga, J. (2015). The Influence of Strategic Management Practices on Performance of Private Construction Firms in Kenya. International Journal of Scientific and Research Publications, 5(6).

Williamson, I., Enemark, S., Wallace, J., \& Rajabifard, A. (2010). Land administration for sustainable development. Paper presented at the FIG Congress 2010-Facing the ChallengesBuilding the Capacity.

Yang, Y. N. (2003). Testing the Stability of Experts' Opinions between Successive Rounds of Delphi Studies.
Yousuf, M. I. (2007). Using experts' opinions through Delphi technique. Practical assessment, research \& evaluation, 12(4), $1-8$.

Yusoff, M. Y. M., \& Halim, N. Z. A. (2012). Country Report: Unleashing the Full Potential of eKadaster on The Cadastral System of Malaysia (E/CONF.102/CRP.3). Retrieved from Bangkok, Thailand: 